\title{
(2) OPEN ACCESS \\ Multiterritorial strokes in the setting of spontaneous heparin-induced thrombocytopaenia syndrome
}

\author{
Christopher Kwan 다, ${ }^{1}$ Jon Reimers, ${ }^{1}$ Cullen o'Gorman, ${ }^{1}$ Robert Bird, ${ }^{2}$ Helen Brown ${ }^{1}$
}

\begin{abstract}
${ }^{1}$ Neurology, Princess Alexandra Hospital Health Service District, Brisbane, Queensland, Australia ${ }^{2}$ Haematology, Princess Alexandra Hospital Health Service District, Woolloongabba, Queensland, Australia
\end{abstract}

Correspondence to

Dr Christopher Kwan; chriskwan88@gmail.com

Accepted 21 December 2021

Check for updates

(c) BMJ Publishing Group Limited 2022. Re-use permitted under CC BY-NC. No commercial re-use. See rights and permissions. Published by BMJ.

To cite: Kwan C, Reimers J, o'Gorman C, et al. BMJ Case Rep 2022;15:e244143. doi:10.1136/bcr-2021244143

\section{SUMMARY}

We present a case study of a 38-year-old man who developed arterial and venous thrombi, resulting in multiterritorial strokes, a pulmonary embolus and a cerebral venous sinus thrombosis in the setting of spontaneous heparin-induced thrombocytopaenia syndrome.

\section{BACKGROUND}

Spontaneous heparin-induced thrombocytopaenia syndrome (HITS) is a very rare phenomenon that occurs due to the presence of antiplatelet factor 4 (PF4) antibodies that activate platelets in the absence of heparin. This case study outlines the presentation, diagnosis and subsequent management of a patient admitted under the department of neurology who was later diagnosed with spontaneous HITS.

\section{CASE PRESENTATION}

A 38-year-old man presented with a 1-week history of worsening headaches and blurred vision. The headaches were described as a dull, throbbing pain in the bilateral occiput, with no change on repositioning and no improvement with paracetamol. $\mathrm{He}$ also reported a dull ache in the right shoulder over a similar period without history of injury.

His previous medical history was significant for hypertension and obesity. He and his family had sore throat and cough 7 days before admission although they tested negative for COVID-19 in the community. He was not on regular medications and was unvaccinated against COVID-19. He lived with his wife and two children, worked in Information Technology and denied drinking alcohol. He used to smoke until 1 month before admission. He was still driving.

On examination, all his vital observations were normal. A relative afferent pupillary defect was detected on the right with dense right eye superior visual field loss noted. No other neurological findings were detected. His cardiovascular, respiratory and abdominal examination was unremarkable.

\section{INVESTIGATIONS}

The patient was initially reviewed by ophthalmology and differential diagnoses included optic neuritis, carotid artery dissection, vasculitis and cerebral venous sinus thrombosis. Neuroimaging showed complete right common, internal and external carotid artery occlusions, multifocal left common carotid artery thrombus, resulting in $75 \%$ stenosis of the left common carotid, with thrombus extending into the proximal left internal carotid artery (ICA) and total occlusion of the left external carotid artery. There was also a cerebral venous sinus thrombosis affecting the right transverse and sigmoid sinuses (see figure 1). There were also multiple small acute grey and white matter infarcts scattered throughout the right anterior and posterior circulations on diffusion-weighted imaging MRI. The right eye visual changes were due to a right retinal artery occlusion. A CT chest and neck angiogram demonstrated the aforementioned right ICA thrombosis and a right lower lobe pulmonary arterial embolus with no evidence of any arterial dissection (see figure 2). Later that day, he developed new left upper limb weakness. CT brain perfusion and angiogram revealed proximal propagation of the right transverse sinus thrombosis and a persistent right carotid thrombosis.

On day 16, the patient developed an acute onset of severe right arm and leg weakness, severe receptive and expressive dysphasia and right-sided neglect with a National Institutes of Health Stroke Scale score of 22 . Repeat CT brain perfusion at that point revealed total occlusion of the left ICA, and new infarcts in the left middle cerebral artery (MCA) and anterior cerebral artery (ACA) territories with occlusive thrombus demonstrated within the inferior division of the M2 segment of the left MCA and within the callossomarginal branch of the left ACA (see figure 3). The vision loss in his right eye (present on admission) had worsened and he developed a new left eye vision loss due to a left retinal artery occlusion rendering him blind in both eyes.

On day 93 into the admission, the patient's rightsided weakness abruptly worsened and he also developed a new right-sided facial droop, sensory neglect and sensory loss. A repeat CT brain perfusion showed new left distal M1 non-opacification and associated new perfusion abnormality in the anterior left MCA territory (see figure 4).

Platelet counts the day prior to his hospital admission were $128 \times 10^{9} / \mathrm{L}$ and declined to $81 \times 10^{9} / \mathrm{L}$ by day 2 of his hospital admission, which occurred prior to initiation of intravenous heparin. Platelet counts remained low at approximately $70 \times 10^{9} / \mathrm{L}$ until day 16 when intravenous dexamethasone was administered: the platelets steadily increased to $212 \times 10^{9} / \mathrm{L}$ by day 23 . On arrival, International Normalised Ratio (INR) was 1.2, prothrombin time was 13 with an elevated fibrinogen level of $4.5 \mathrm{~g} / \mathrm{L}$ (reference range $1.7-4.5 \mathrm{~g} / \mathrm{L}$ ). On day 16 , his D-Dimer level was $5.59 \mathrm{mg} / \mathrm{L}$ (reference range $0.02-0.49 \mathrm{mg} / \mathrm{L}$ ) while on heparin. On day 16 , PF4 antibody tests were collected (when intravenous 


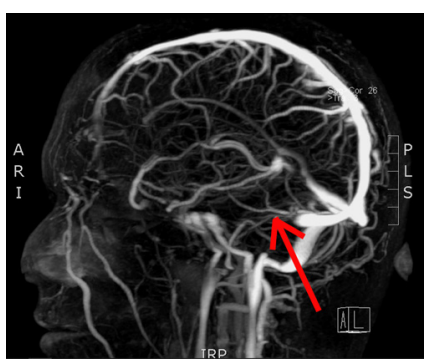

Figure 1 MR brain and orbits showing dural sinus thrombosis of right transverse sinus. A, anterior; P, posterior; R, right; L, left; I, inferior; S, superior.

heparin was ceased). On day 18 , the patient tested positive to ID-heparin PF4 antibodies (CARD test), with equivocal heparin PF4 IgG antibodies (ACU-STAR). A provisional diagnosis of spontaneous HITS was made given the presentation of recurrent thromboses and thrombocytopaenia prior to administration of intravenous heparin, and the presence of PF4 antibodies (detected on day 18, with samples being collected on day 16 when intravenous heparin was ceased). Functional HIT testing (including a ${ }^{14} \mathrm{C}$-serotonin release assay) was performed, which revealed $104 \%$ serotonin release at $0.1 \mathrm{U} / \mathrm{mL}$ heparin (reference range $0 \%-20 \%$ ), and $0 \%$ serotonin release at $100 \mathrm{U} / \mathrm{mL}$ heparin (reference range $0 \%-20 \%$ ) on day 93 (blood collected on day 24 while off heparin).

Other tests for thrombophilia including for antiphospholipid syndrome (lupus anticoagulant, anticardiolipin and anti-beta 2 glycoprotein 1 antibodies), genetic thrombophilia (Factor V Leiden, antithrombin deficiencies, protein $\mathrm{C}$ and $\mathrm{S}$ deficiencies and prothrombin mutation), ADAMTS13, PNH, JAK2, vasculitis (including hepatitis B, C, HIV, Erythrocyte Sedimentation Rate (ESR), C-Reactive Protein (CRP), Extractable Nuclear Antigen (ENA) Antibodies, Anti-Nuclear Antibodies (ANA), Anti-Neutrophil Cytoplasmic Antibodies (ANCA), complement), serum COVID-19 IgG (Enzyme Immunoassay - EIA) and nasopharyngeal swab COVID-19 PCR (GeneXpert). A high factor VIII level was also detected at $3.12 \mathrm{U} / \mathrm{mL}$ (reference range $0.50 \mathrm{U} / \mathrm{mL})$.

No malignancy was detected on imaging including US liver and scrotum, CT chest, abdomen and pelvis and full-body Fulorodeoxyglucose Position Emission Tomography (FDG-PET) scan. Bone marrow aspirate was considered but it was deemed too high risk for the patient given the need for aggressive anticoagulation at the time. Peripheral blood and urine tests found no other features suggestive of a lymphoproliferative disorder or

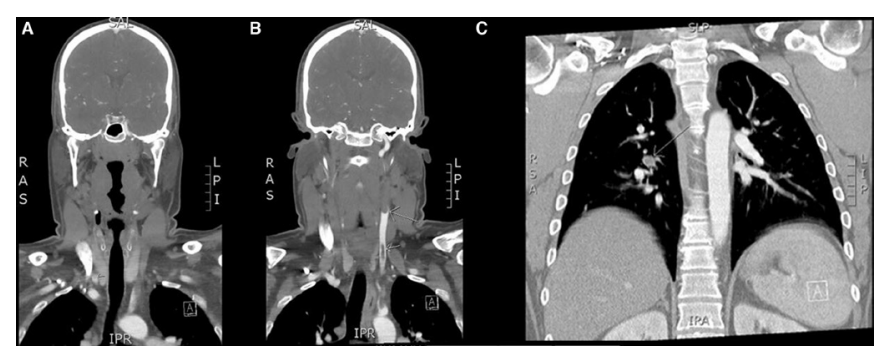

Figure 2 Day 2 CT chest and neck angiogram demonstrating complete occlusion of the right common carotid, internal and external carotid artery (A), and multifocal left common carotid artery thrombosis with total occlusion of left internal carotid artery (B). It also demonstrated right lower lobe pulmonary arterial embolus (C). A, Anterior; L, Left; I, Inferior; P, Posterior; R = Right; S, Superior.

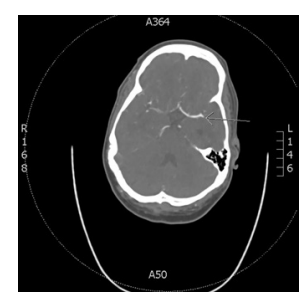

Figure 3 CT brain perfusion and angiogram on day 16, showing left MCA and ACA territories with occlusive thrombi demonstrated within the inferior division of the M2 segment of the left MCA and within the callossomarginal branch of the left ACA. There was also a complete left ICA occlusion. ACA, anterior cerebral artery; ICA, internal carotid artery; MCA, middle cerebral artery.

paraproteinaemia. Cardiac telemetry, chest X-ray and transthoracic echocardiogram with bubble study were normal with no evidence of cardiac failure or structural abnormalities (including no evidence of a patent foramen ovale).

\section{DIFFERENTIAL DIAGNOSIS}

Differential diagnoses included:

- Carotid and subclavian artery dissection (however, this would not explain the cerebral venous sinus thrombosis)

- Antiphospholipid syndrome

- Postinfectious thrombosis with thrombocytopaenia syndrome

- Malignancy-driven thrombosis

- Atrial fibrillation, cardiac failure, congenital cardiac shunts (however, this would not explain the cerebral venous sinus thrombosis).

\section{TREATMENT}

The initial working diagnosis was an inflammatory optic neuritis given the patient's young age. Further investigations were planned to determine the underlying cause. He was not commenced on any steroids at that time while awaiting his test results. Chemical Deep Vein Thrombosis (DVT) prophylaxis was not commenced on admission given, he was independently mobile.

On day 2 of his hospital admission, the diagnosis was revised to an ischaemic optic neuritis due to retinal artery occlusion in the context of both arterial and venous thrombi evident on neuroimaging, with transverse sinus thrombosis propagation evident on follow-up imaging and declining platelet counts. After discussion with haematology on day 2 , intravenous heparin with an aPTT target of 65-90 was commenced, and aspirin $100 \mathrm{mg}$ daily was commenced for the management of new thromboses on the proviso that platelet counts do not drop below $50 \times 10^{9} / \mathrm{L}$.

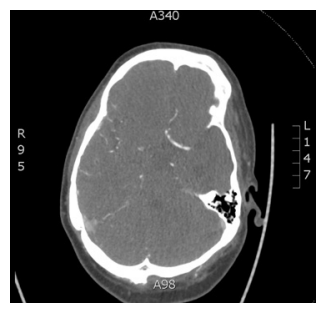

Figure 4 CT brain perfusion and angiogram on day 93, showing new left distal M1 non-opacification and associated new perfusion abnormality in the anterior left MCA territory. MCA, middle cerebral artery. 


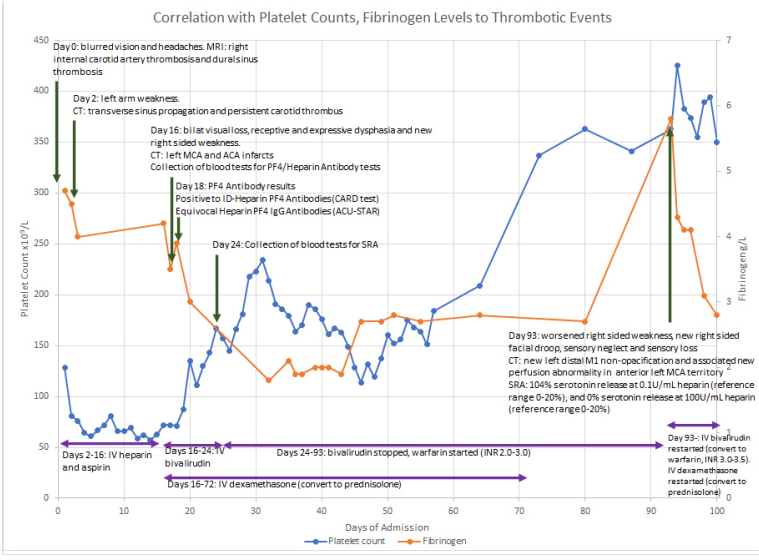

Figure 5 Summary of platelet counts, timing of treatment administration and thrombotic events. ACA, anterior cerebral artery; MCA, middle cerebral artery; SRA, Serotonin Release Assays.

On day 16, when the patient suffered a further stroke the IV heparin was ceased and changed to bivalirudin with activated partial thromboplastin time (aPTT) range to transition to warfarin (INR target 2.0-3.0) due to the development of further strokes. Intravenous dexamethasone $8 \mathrm{mg}$ two times per day was commenced and within 7 days, platelets increased to $212 \times 10^{9} / \mathrm{L}$. The dexamethasone was transitioned to prednisolone, $25 \mathrm{mg} /$ day with weaning dose, and eventually stopped on day 72 .

On day 93, the patient developed a further stroke while the platelet count remained normal at $363 \times 10^{9} / \mathrm{L}$ and on therapeutic warfarin (INR 2.7). At that time, the ${ }^{14} \mathrm{C}$-serotonin release assay tested positive, which further supported the provisional diagnosis of spontaneous HITS, given the patient presented with thromboses on admission with thrombocytopaenia and the absence of heparin administration on admission. Due to the new strokes, intravenous bivalirudin was recommenced and warfarin was reintroduced with a higher INR target range (3.0-3.5). Intravenous dexamethasone $4 \mathrm{mg}$ two times per day was recommenced and then converted to prednisolone $40 \mathrm{mg} /$ day. To this date, the patient's platelet count remained normal.

\section{OUTCOME AND FOLLOW-UP}

The aforementioned tests and interventions have been summarised in figure 5. The patient continued with inpatient rehabilitation and was discharged from hospital 4 months since initial presentation with normal platelet counts. He continues to undergo outpatient rehabilitation. He remains blind with minor right-sided neglect and fine motor weakness, although his functional independence and cognition are improving. His prednisolone was ceased 5 months after discharge. He remains on warfarin (target INR 3-3.5) with a current dose of 6-6.5 mg/ day; he is planned for transition to a direct oral anticoagulant (DOAC) in another 4 months.

\section{DISCUSSION}

Spontaneous HITS is a very rare phenomenon, involving the presence of anti-PF4-polyanion IgG antibodies that activate platelets in the absence of heparin. ${ }^{1}$ This has become an increasingly recognised problem seen in patients who develop spontaneous thromboses without having been administered heparin recently or even at all. These platelet-activating properties can be seen in both spontaneous HITS, vaccine-induced thrombotic thrombocytopaenia and a minority of heparin-dependent HITS. ${ }^{1}$
The Brighton Collaboration interim case definition of thrombosis with thrombocytopaenia syndrome includes a platelet count of $<150 \times 10^{9} / \mathrm{L}$ without history of heparin administration within 100 days, and imaging, surgical or pathological findings consistent with thrombosis or thromboembolism.

In standard HITS, PF4 antibodies are activated at pharmacologic unfractionated heparin (UFH) concentrations (0.1-0.3 IU/ $\mathrm{mL}$ ) and remain inert in the absence of UFH. ${ }^{1}$ However, in spontaneous HITS, platelets are still activated even in the absence of heparin. ${ }^{1}$ Many laboratories only perform platelet-activated assays at $0.1-0.5 \mathrm{IU} / \mathrm{mL} \mathrm{UFH}$ and at $100 \mathrm{IU} / \mathrm{mL}$ heparin, so spontaneous HITS could be under-recognised. ${ }^{1}$ In this setting, the lab performed the ${ }^{14} \mathrm{C}$-serotonin release assay in the absence of intravenous heparin with a positive result of $104 \%$ serotonin release at $0.1 \mathrm{U} / \mathrm{mL}$ heparin and $0 \%$ serotonin release at $100 \mathrm{U} /$ $\mathrm{mL}$ heparin.

Evidence for the management of spontaneous HITS is limited and is based on anecdotal experience. ${ }^{1}$ As with HITS, heparin should be avoided. ${ }^{1}$ Most patients with spontaneous HITS are usually no longer receiving heparin or have never received heparin. ${ }^{1}$ Administration of heparin in spontaneous HITS may have variable effects on thrombosis, depending on whether or not the PF4 antibodies are heparin-dependent or not. ${ }^{1}$

During initial platelet depletion and active thrombosis, warfarin should be avoided. ${ }^{2}$ Warfarin can cause further protein $\mathrm{C}$ depletion, exacerbating hypercoagulopathy with a prolonged APTT confounding this. ${ }^{2}$ Warfarin should be reversed in this setting to avoid further deterioration. ${ }^{2}$ Alternative forms of anticoagulation such as DOACs or IV anticoagulation with argatroban, bivalirudin, danaparoid or fondaparinux may be used to treat the hypercoagulable state in spite of severe thrombocytopaenia, though evidence is limited. ${ }^{23}$ To assess for effectiveness of initial anticoagulation, serial measurements of fibrinogen and fibrin D-dimer levels are performed; increasing levels of fibrinogen and fibrin D-dimer levels alongside declining platelet counts indicate failure to effectively anticoagulate, and higher doses of anticoagulant may be needed. ${ }^{1}$ On the day prior to hospital admission, the patient's platelet count was $128 \times 10^{9} / \mathrm{L}$, fibrinogen was $4.5 \mathrm{~g} / \mathrm{L}$ before administration of intravenous heparin on day 2 of his hospital admission. On day 16 and on intravenous heparin, the patient's platelet count was $71 \times 10^{9} / \mathrm{L}$, fibrinogen level was elevated at $4.5 \mathrm{~g} / \mathrm{L}, \mathrm{D}$-dimer of $5.18 \mathrm{mg} /$ $\mathrm{mL}$, which increased to $5.59 \mathrm{mg} / \mathrm{mL}$ (reference range $0.02-0.49$ ) later that afternoon: by then the intravenous heparin was ceased and intravenous dexamethasone was commenced. By day 24, the fibrinogen count declined to $1.8 \mathrm{~g} / \mathrm{L}$ and platelet count improved to $212 \times 10^{9} / \mathrm{L}$.

If a DOAC is chosen for initial anticoagulation, then this can be continued without any further changes to management. If argatroban, bivalirudin, danaparoid or fondaparinux were used for initial anticoagulation, then this will be transitioned to either warfarin or a DOAC. If warfarin is chosen as the longer term anticoagulation option, then this can be initiated on the patient is stably anticoagulated and the platelet count has recovered to at least $150 \times 10^{9} / \mathrm{L}^{4-6}$ There should be a minimum of 5 days of overlapping therapy with warfarin and alternative anticoagulation and the INR should be between 2.0 and 3.0 before the alternative anticoagulation is discontinued. ${ }^{5}$ It is important to note that prolonged thrombocytopaenia in spontaneous HITS can be due to ineffective anticoagulation or drug cross-reactivity. ${ }^{1}$ If a decision is made to transition to a DOAC, then it is suggested to continue alternative intravenous anticoagulation for a minimum of 5 days before transitioning to the DOAC though there is no evidence to support this strategy. Our patient had a significant 
thrombotic burden, so the decision was to use intravenous anticoagulation with bivalirudin with the goal of transitioning to warfarin once platelet counts had recovered.

Immunosuppressive strategies such as corticosteroids, rituximab, plasmapheresis and intravenous immunoglobulin may be considered in patients with persistent thrombocytopaenia and recurrent thrombosis. ${ }^{7}$ These therapies may reduce platelet activation by immunosuppression of PF4/heparin antibodies. Plasmapheresis should reduce spontaneous HITS antibodies and improve outcomes, and anecdotal reports have shown some improvement after plasmapheresis. ${ }^{8}$ One report describes a patient with spontaneous HITS associated with thrombocytopaenia and thrombotic stroke, whose platelet count rapidly normalised after administration with $1 \mathrm{~g} / \mathrm{kg} /$ day for 2 days. ${ }^{9}$ Unfortunately, there are no randomised controlled trials being performed to evaluate the effectiveness of these immunosuppressive options.

\section{Learning points}

To summarise, this case study generates a few learning points:

- Spontaneous heparin-induced thrombocytopaenia syndrome (HITS) presents similarly to HITS with hypercoagulopathy and thrombocytopaenia but can occur without an immediate temporal association with heparin.

- The principles of the management of spontaneous HITS are largely similar to HITS, where alternative anticoagulation to heparin and warfarin is preferred.

- Immunotherapy such as plasmapheresis and intravenous immunoglobulin may arrest spontaneous HITS antibody platelet activation, but evidence is anecdotal.

- Patients who are highly thrombotic, such as our patient with his multiterritorial strokes, should be considered for investigation for spontaneous HITS, if other tests for hypercoagulability are negative.

Acknowledgements Patient under the care of JR, CoG, RB, HB. Manuscript authorship and editing by CK, JR, COG, RB, HB.

Contributors $C K$ gathered data, attended to patient and wrote the manuscript. $J R, C O G, H B$ and RB provided clinical care to patient and proof-read the manuscript
(NOTE: I wish to submit Dr Cullen o'Gorman as third author: Staff Specialist Neurologist Princess Alexandra Hospital Health Service District, Neurology199 Ipswich Road, Woolloongabba Brisbane, QLD, AUS 41020731762111).

Funding The authors have not declared a specific grant for this research from any funding agency in the public, commercial or not-for-profit sectors.

Competing interests None declared.

Patient consent for publication Consent obtained from next of kin

Provenance and peer review Not commissioned; externally peer reviewed.

Open access This is an open access article distributed in accordance with the Creative Commons Attribution Non Commercial (CC BY-NC 4.0) license, which permits others to distribute, remix, adapt, build upon this work non-commercially, and license their derivative works on different terms, provided the original work is properly cited and the use is non-commercial. See: http://creativecommons.org/ licenses/by-nc/4.0/.

Case reports provide a valuable learning resource for the scientific community and can indicate areas of interest for future research. They should not be used in isolation to guide treatment choices or public health policy.

\section{ORCID ID}

Christopher Kwan http://orcid.org/0000-0002-3775-4370

\section{REFERENCES}

1 Greinacher A, Selleng K, Warkentin TE. Autoimmune heparin-induced thrombocytopenia. J Thromb Haemost 2017;15:2099-114.

2 Warkentin TE. Should vitamin K be administered when HIT is diagnosed after administration of coumarin? J Thromb Haemost 2006;4:894-6.

3 Warkentin TE, Pai M, Linkins L-A. Direct oral anticoagulants for treatment of HIT: update of Hamilton experience and literature review. Blood 2017;130:1104-13.

4 Wallis DE, Workman DL, Lewis BE, et al. Failure of early heparin cessation as treatment for heparin-induced thrombocytopenia. Am J Med 1999;106:629-35.

5 Linkins L-A, Dans AL, Moores LK, et al. Treatment and prevention of heparin-induced thrombocytopenia: antithrombotic therapy and prevention of thrombosis, 9th ed: American College of chest physicians evidence-based clinical practice guidelines. Chest 2012;141:e495S-530

6 Warkentin TEet al. The pathogenesis of venous limb gangrene associated with heparininduced thrombocytopenia. Ann Intern Med 1997;127:804-12.

7 Schell AM, Petras M, Szczepiorkowski ZM, et al. Refractory heparin induced thrombocytopenia with thrombosis (HITT) treated with therapeutic plasma exchange and rituximab as adjuvant therapy. Transfus Apher Sci 2013;49:185-8

8 Horlait G, Minet V, Mullier F, et al. Persistent heparin-induced thrombocytopenia: danaparoid cross-reactivity or delayed-onset heparin-induced thrombocytopenia? A case report. Blood Coagul Fibrinolysis 2017;28:193-7.

9 Irani $M$, Siegal $E$, Jella $A$, et al. Use of intravenous immunoglobulin $G$ to treat spontaneous heparin-induced thrombocytopenia. Transfusion 2019;59:931-4.

Copyright 2022 BMJ Publishing Group. All rights reserved. For permission to reuse any of this content visit

https://www.bmj.com/company/products-services/rights-and-licensing/permissions/

BMJ Case Report Fellows may re-use this article for personal use and teaching without any further permission.

Become a Fellow of BMJ Case Reports today and you can:

- Submit as many cases as you like

- Enjoy fast sympathetic peer review and rapid publication of accepted articles

- Access all the published articles

Re-use any of the published material for personal use and teaching without further permission

Customer Service

If you have any further queries about your subscription, please contact our customer services team on +44 (0) 2071111105 or via email at support@bmj.com.

Visit casereports.bmj.com for more articles like this and to become a Fellow 